\title{
Pericardial constriction caused by primary mesothelioma
}

\author{
MICHAEL J LLEWELLYN, MARK W ATKINSON, BRIAN FABRI \\ From the Regional Adult Cardiothoracic Unit, Broadgreen Hosital, Liverpool
}

SUMMARY Primary pericardial mesothelioma is an extremely rare tumour. This case illustrates the typical late presentation with symptoms and signs of constrictive pericarditis. An unusual feature was complete encasement of the heart by tumour. No satisfactory treatment is availablos

\section{Case report}

A 69 year old retired seaman gave a two month history of progressively worsening breathlessness and central chest discomfort on effort. There was associated weight loss, anorexia, night sweats, and pronounced peripheral oedema. Symptoms were partly relieved by diuretics and vasodilators.

Previous illnesses included longstanding, but well controlled, hypertension (treated with atenolol and hydralazine) and resection of an enlarged prostate two years before presentation, in which histological examination showed foci of well differentiated prostatic adenocarcinoma.

On examination he was unwell, slightly jaundiced, and dyspnoeic at rest. The pulse was regular and of small volume, and the blood pressure was $90 / 60 \mathrm{~mm} \mathrm{Hg}$. The jugular venous pulse was elevated to the angle of the jaw, with sharp " $y$ " descent and there was pitting oedema up to the knees. The cardiac apex was impalpable and the heart sounds quiet without added sounds or murmurs. The lungs were moderately congested with a small right pleural effusion.

A chest radiograph showed cardiac enlargement (cardiothoracic ratio $58 \%$ ), pulmonary venous congestion, linear collapse, and bilateral pleural effusions. No pleural plaques or lung tumour were seen. The electrocardiogram showed low voltage QRS complexes with non-specific $T$ wave changes. Echocardiography demonstrated thickened pericardium with small anterior and posterior peri-

Requests for reprints to Dr Michael J Llewellyn, Regional Adult Cardiothoracic Unit, Broadgreen Hospital, Thomas Drive, Liverpool L14 3LB. cardial effusions, normal valves without vegetation $\overrightarrow{\mathrm{s}_{3}}$ and satisfactory ventricular contractility.

Initial investigation showed: haemoglobi角 $12.8 \mathrm{~g} / \mathrm{dl}$; white cell count $10.8 \times 10^{9} / 1$; sodiunt $128 \mathrm{mmol} / \mathrm{l}$; urea $21.7 \mathrm{mmol} / \mathrm{l}$; creatinine $211 \mathrm{mmol} / \mathrm{l}$; concentrations of liver transaminases were slightly raised; lactate dehydrogenase $189 \mathrm{U}$ (normal 80-160 U/1); alkaline phosphatase 133 U/ Blood, sputum, and urine culture were sterile. Vir titres, tuberculin test, and autoantibody screen werf negative. Acid phosphatase concentration was nof raised. Pleural aspiration drew clear yellow fluiक protein content $35 \mathrm{~g} / \mathrm{l}$; cytology showed mesotheliä cells.

At cardiac catheterisation diastolic pressures in af chambers were almost equal (right atrium mean $2 z^{2}$ right ventricle $40 / 22$; pulmonary artery $45 / 30$; mea: pulmonary capillary wedge 24 ; left ventricle $100 / 22_{-2}$ aorta $100 / 80 \mathrm{~mm} \mathrm{Hg}$.) Cineangiography showeä. small and well contracting left and right ventricles with considerable limitation of diastolic filling Coronary arteriography showed a $75 \%$ proxima stenosis of the anterior descending branch of the leff coronary artery.

At thoractomy the heart was found to be supo rounded by thick white tumour masses, which hå spread to the adjacent mediastinal nodes and pleuras Resection was impossible and the patient died several hours after return from the operating theatre.

At postmortem the whole heart was found to bo encased by tumour, with pericardium adherent to the epicardium forming a continuous band of white tissue $1 \mathrm{~cm}$ thick (fig 1 ). Several nodules of tumouf surrounded the great vessels and the heart plus tumour weighed over $1 \mathrm{~kg}$. Numerous small pleur nodules of tumour were present, and none was 


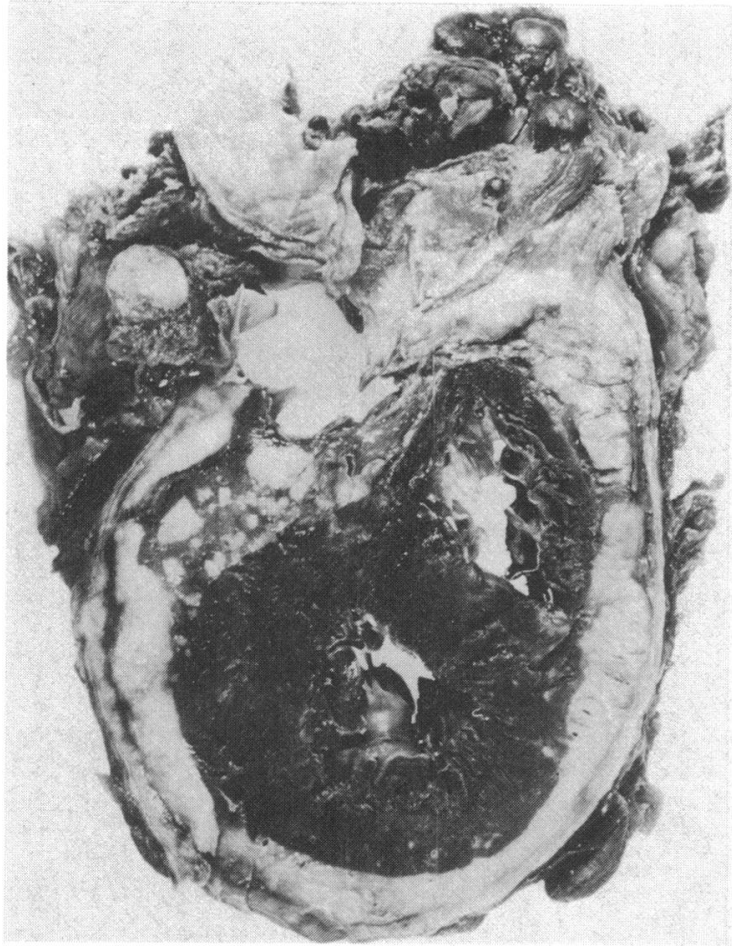

Fig 1 Transverse section of heart and great vessels showing complete encasement of heart by tumour.

larger than $1 \mathrm{~cm}$ in diameter. There was no evidence of residual prostatic tumour or of any pelvic or abdominal neoplasia or lymphadenopathy.

The histological appearances of most of the pericardial tumour indicated an anaplastic carcinoma that had infiltrated the myocardium (fig 2). There were, however, numerous areas showing papillary differentiation (fig 3a), acinar elements (fig 3b), mesothelial differentiation (fig 3c), and frankly sarcomatous differentiation (fig 3d). Neutral mucin stains (periodic acid Schiff diastase) and immunoperoxidase stains for prostatic acid phosphatase, prostatic specific antigen, and carcinoembryonic antigen were negative. These features meet the diagnostic criteria for malignant mesothelioma. ${ }^{1}$

\section{Discussion}

Primary tumours of the pericardium are extremely rare; one of the largest necropsy series of recent years gives an incidence of $0.0022 \%$ in 500000 cases. ${ }^{2}$ Mesothelioma is probably the commonest type, followed by sarcoma, teratoma, fibroma, lipoma, and angioma. ${ }^{3}$ The incidence in both sexes is almost equal, with an age range of 1-79 years.
The tumour is commonly diagnosed at a late stage and often results in evidence of constriction caused by tumour expansion or associated serous or haemorrhagic pericardial effusion. The diagnosis in this case was suspected because of thickened pericardium seen on the echocardiogram; and in view of the previous history of malignancy, a secondary rather than primary tumour seemed more likely. Although cardiac catheterisation can confirm pericardial constriction and indicates ventricular function, definitive diagnosis is often not made until thoractomy. The pleural exudate obtained in this case contained non-specific mesothelial cells and was clearly a pointer to the tumour. Pericardial aspiration was not attempted before operation but would probably have produced a dry tap, perhaps a helpful feature in differential diagnosis.

Radioisotope scanning with gallium or technetium may be used to detect malignant pericardial effusion but results are not regarded as being highly specific. ${ }^{3}$ Computed tomography may well be helpful in distinguishing tumour from fluid in the pericardial space. ${ }^{4}$

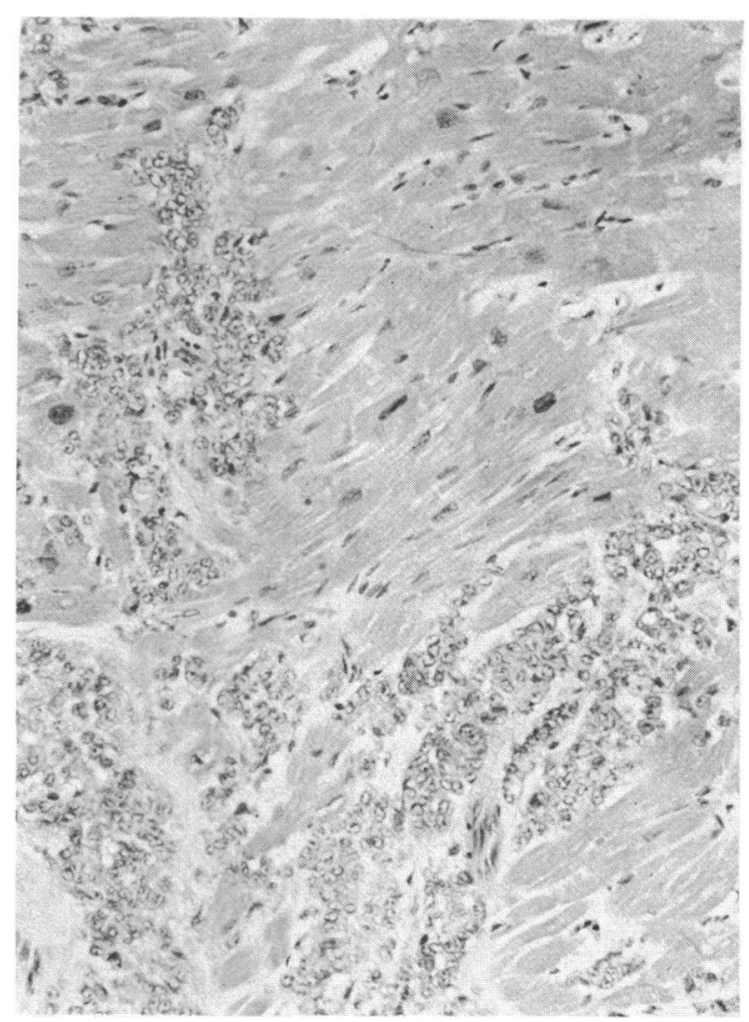

Fig 2 Photomicrograph showing myocardial infiltration by tumour. 


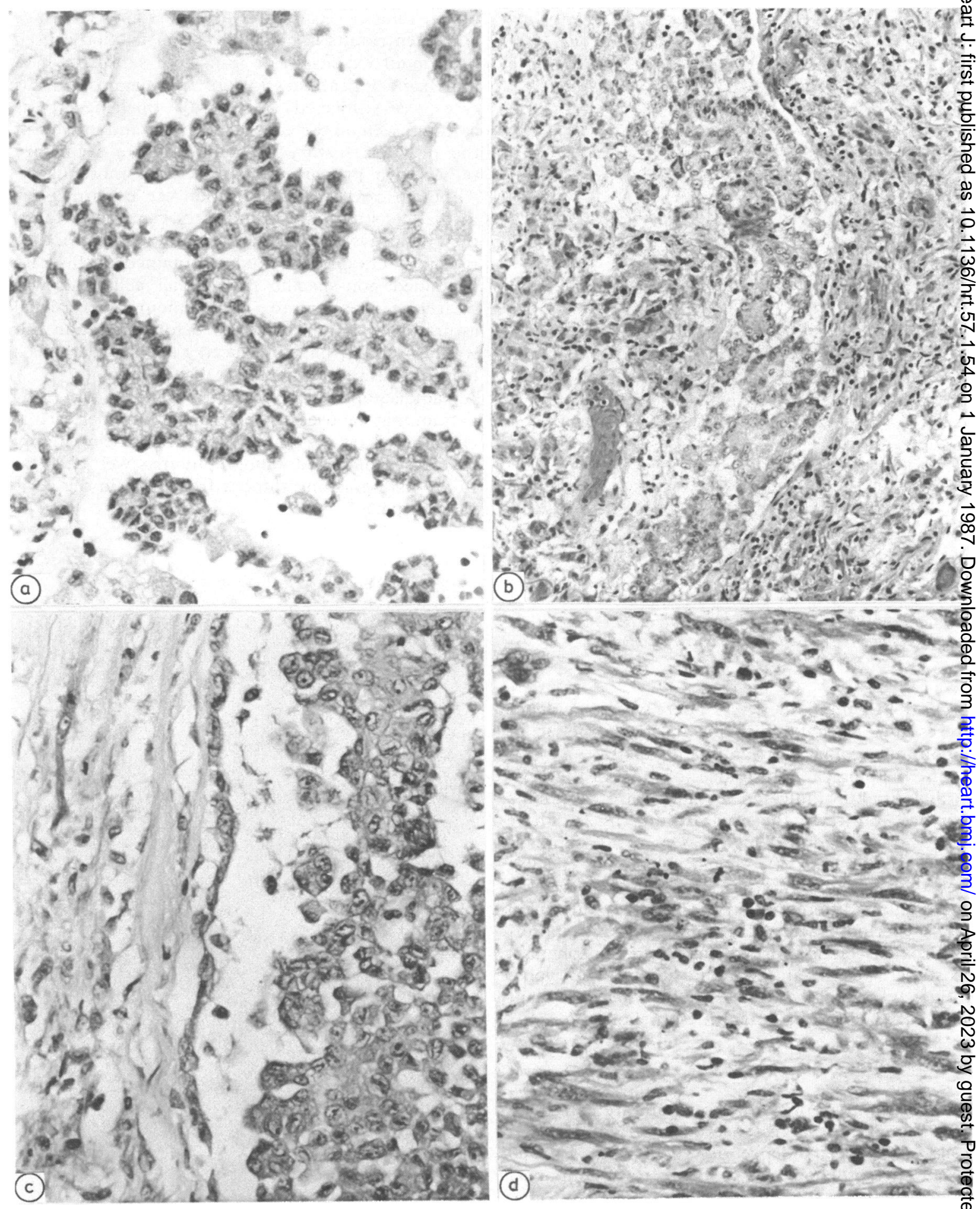

Fig 3 Photomicrographs (a) papillary elements, (b) acinar elements, and showing (c) mesothelial and (d) sarcomatous $\stackrel{\mathbb{D}}{\varrho}$ differentiation. 
The gross pathological appearance may be of a localised mass, solid or cystic or angiomatous, or of diffuse nodules. Complete encasement of the heart by tumour is an unusual feature and has been rarely reported. ${ }^{4-8}$ The pericardial tumour is often adherent to or may invade the myocardium. ${ }^{9}$ The tumour can also invade the conducting tissue or coronary arteries, or compress the great vessels. Local spread is common, but extrathoracic metastasis is extremely rare. In one review stringent criteria were applied to the diagnosis of mesothelioma when the pericardium was the postulated primary site, ${ }^{10}$ particularly when numerous pleural metastases were present. The clinical presentation and pathological distribution of tumour must, therefore, be considered together when deciding on the diagnosis and primary site. Histological differentiation is often difficult because of the pleomorphic nature of the tumour.

Possibilities for treatment are usually limited by late detection. Complete tumour resection is virtually impossible so operation is usually confined to attempts to relieve obstruction. The results of systemic chemotherapy are disappointing; but if associated pericardial effusion is present local instillation of cytotoxic drugs or sclerosing agents can be helpful. Radiotherapy may temporarily reduce the size of the tumour.

There has been no clear association between asbestos exposure and pericardial mesothelioma. This is probably because the paucity of recorded cases has not allowed an adequate epidemological study. As in many cases, this diagnosis was made after death and the relevant history was not available.
We thank Dr R G Charles and Mr J B Meade for permission to report this case and Dr W Kenyon and Dr F Whitwell for their help with histological assessment.

\section{References}

1 Jones JSP, Lund C, Plantey HT. Colour atlas of mesothelioma. Lancaster: MTP Press, 1985:15-6.

2 Cohen JL. Neoplastic pericarditis. Cardiovase Clin 1976;7:257-69.

3 Darsee JR, Braunwald E. Diseases of the pericardium. In: Braunwald E, ed. Heart disease, a textbook of cardiovascular medicine. Philadelphia, London, Toronto: WB Saunders, 1980:1563.

4 Yilling FP, Schlant RC, Hertzler GL, Krzyniak R. Pericardial mesothelioma. Chest 1982;81:520-3.

5 Pietra GG, Silber E, Levin B, Pick A. Clinical pathologic conference. Am Heart $\mathcal{F}$ 1968;75:545-58.

6 Elguezabal A, Parry JP, Depace NL. Massive metastatic cardiac tumour encasement with pericardial constriction. F Med Soc NF 1980;77:820-4.

7 Miscia VF, Holsinger JW, Mathers DH, Eliot RS. Primary pericardial tumour masquerading as constrictive pericarditis. $\mathcal{F} A M A$ 1974;230:722.

8 Kirwan M, Blake S, Neligan M, et al. Cardiac constriction due to malignant disease of the pericardium. Ir $\mathcal{F}$ Med Sci 1983;152:454-5.

9 Sytman AL, Macalpin RN. Primary pericardial mesothelioma: report of two cases and review of the literature. Am Heart f 1971;81:760-9.

10 Anderson JA, Hansen BF. Primary pericardial mesothelioma. Dan Med Bull 1974;21:195-200. 